\title{
Investigation of the effect of a time window on the accuracy of an estimated impulse response
}

\author{
Masato Abe, ${ }^{*}$ Chun-Duck Kim,** and Ken'iti Kido*** \\ *Education Center for Information Processing, Tohoku University, \\ Kawauchi, Sendai, 980 Japan \\ **Department of Electronics and Communication Engineering, \\ National Fisheries University of Pusan, \\ 599-1, Daeyeon-Dong, Nam-ku, Pusan, 608 Korea \\ ***Research Center for Applied Information Sciences, Tohoku University, \\ 2-1-1, Katahira, Sendai, 980 Japan
}

(Received 30 October 1985)

\begin{abstract}
The present paper describes the effect of a time window on the accuracy of impulse response estimation using the cross-spectral technique. Time windows used in this technique have been investigated both for time discrimination and for frequency characteristics (i.e., band width of the main lobe and magnitude of the side lobes). However, such investigations have not fully accounted for why the accuracy of estimated impulse responses is decreased. This paper describes those reasons, and recommends what type of time window should be used to accurately estimate the impulse response for two typical cases: one, where the transfer function is expressed as a simple time delay; and the other, where the impulse response is represented by an exponentially decaying white noise-the most simple model of an impulse response of a room.
\end{abstract}

PACS number: 43. $60 .-\mathrm{c}$

\section{INTRODUCTION}

The cross-spectral technique ${ }^{1)}$ is a useful method for estimating the impulse response of a system if both the input signal and its response can be obtained. When we estimate an impulse response by this technique using a continuous signal as the test input signal, estimation error is inevitable since we must cut both the input and output signals into many segments using finite length time windows. The effect of time windows has been investigated previously for time discrimination and for frequency characteristics, such as the band width of the main lobe and the magnitude of the side lobes. ${ }^{2)}$ However, these investigations have not accounted sufficiently for the effect of a time window on the accuracy of an estimated impulse response. Here in this paper, we describe first the reasons why the accuracy of an estimated impulse response is decreased by the crossspectral technique using a continuous test signal. Next we recommend what type of time window should be used to achieve higher accuracy.

Both the input and output signals are first cut out by means of time windows before computing the Discrete Fourier Transforms (DFT). The following 3 problems are inevitable unless the impulse response is represented by a delta function $d(t)$ with no delay: (a) an output time window involves a response to a signal which is not contained in the input time window; (b) the whole response to the signal involved in the input time window is not always contained in the output time window; (c) the response to the signal involved in the input time window is modulated by the output time window. These are the reasons why the accuracy of an estimated impulse response is decreased. 
The present paper describes these reasons in detail and investigates, in the following two useful cases, the type of time window by which the accuracy of an estimated impulse response is not so debased: (1) an input signal is a white noise and an impulse response is represented by a delta function $d\left(t-T_{\mathrm{d}}\right)$ with a time delay $T_{\mathrm{d}}$ : (2) the input signal is a white noise and the impulse response is represented by an exponentially decaying white noise, $\exp [-3 t]$ $\left.\left(T_{0} \log _{10} e\right)\right] w(t)$ - this is the simplest model of an impulse response of a room, where $T_{0}$ is a reverberation time and $w(t)$ is a white noise.

\section{DECREASE IN THE ACCURACY OF AN ESTIMATED IMPULSE RESPONSE}

Here, the impulse response of a system is represented by $h(t)$. Even if noise is superimposed on the response, the impulse response is correctly estimated using the cross-spectral technique under the condition that both the input signal and its whole response are observed. However, the whole response cannot always be observed, since the length of a time window is finite.

First, the cross-spectral technique is explained below. As shown in Fig. 1 (a), a continuous input signal $x(t)$ drives a system, and the output $y(t)$ is obtained. (No external noise is assumed.) In the cross-spectral technique, both the input and output signals are cut out by adequate time windows. In Fig. $1(\mathrm{~b}), \hat{x}(t)$ and $\hat{y}(t)$ are the cut-out signals of $x(t)$ and $y(t)$, respectively, and $\hat{h}(t)$ the estimated impulse response of the system. This means that the impulse response is estimated so that the following equation is established:

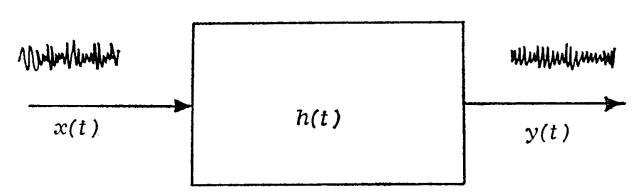

(a)

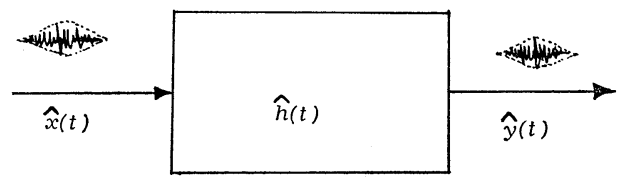

(b)

Fig. 1 Block diagram of estimating an impulse response.

$$
\hat{y}(t)=\hat{x}(t) * \hat{h}(t),
$$

where $*$ denotes the convolution integral. Since the cut-out signals are not always the same as the original signals, an estimation error is inevitable. Next the estimation error is investigated in detail.

The relation between the response and the time window is considered for the case where the input signal is an impulse and the impulse response to be estimated is an exponentially decaying signal, as shown in Figs. 2 (a), (b) and (c). In case (a) shown in
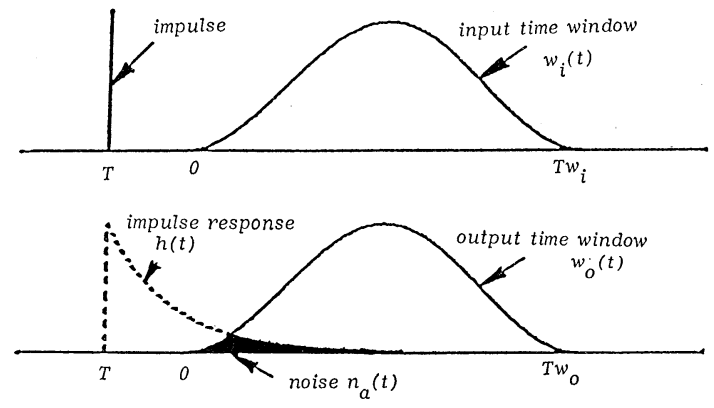

(a)
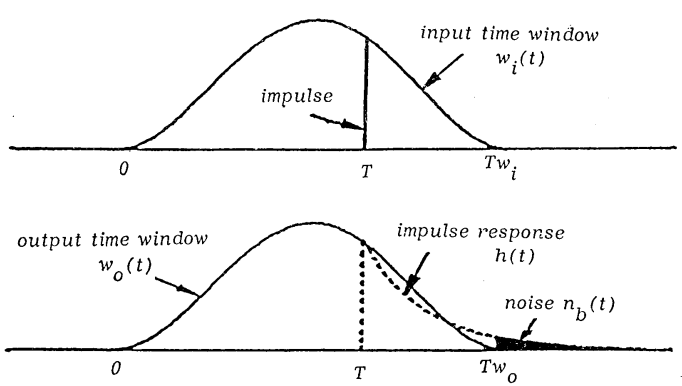

(b)
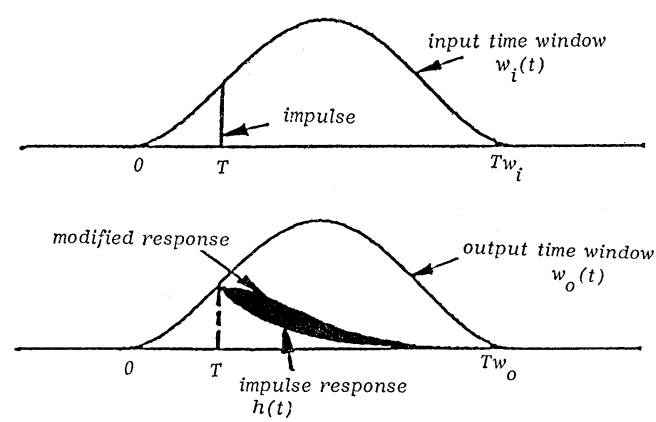

(c)

Fig. 2 Reason why a noise is superimposed in spite of no external noise. 


\section{ABE et al: : A NEW INVESTIGATION OF A TIME WINDOW}

Fig. 2 (a), the cut-out input and output signals, $\hat{x}(t)$ and $\hat{y}(t)$ are expressed as follows:

$$
\begin{gathered}
\hat{x}(t)=0, \\
\hat{y}(t)= \begin{cases}h(t-T) w_{\mathrm{o}}(t), & 0 \leq t \leq T w_{\mathrm{o}} \\
0, & \text { otherwise },\end{cases}
\end{gathered}
$$

where $T$ is the position of the impulse and $w_{0}(t)$ is an output time window with a length $T w_{0}$. Since the cut-out input signal $\hat{x}(t)$ is equal to 0 in this case, the ideal response, $s_{\mathrm{a}}(t)$ should be expressed as follows:

$$
s_{\mathrm{a}}(t)=0 .
$$

However, the cut-out output signal, $\hat{y}(t)$ shows a response, that is, the shaded section in the bottom figure. The shaded section behaves like a noise. The noise, $n_{\mathrm{a}}(t)$ representing the shaded section are expressed as follows:

$$
n_{\mathrm{a}}(t)= \begin{cases}h(t-T) w_{\mathrm{o}}(t), & 0 \leq t \leq T w_{\mathrm{o}} \\ 0, & \text { otherwise } .\end{cases}
$$

In cases (b) and (c) shown in Figs. 2 (b) and (c), the cut-out input and output signals are expressed as follows:

$$
\begin{gathered}
\hat{x}(t)= \begin{cases}w_{\mathrm{i}}(T), & t=T \\
0, & \text { otherwise, }\end{cases} \\
\hat{y}(t)= \begin{cases}h(t-T) w_{\mathrm{o}}(t), & 0 \leq t \leq T w_{\mathrm{o}} \\
0, & \text { otherwise, }\end{cases}
\end{gathered}
$$

where $w_{\mathrm{i}}(t)$ is an input time window with a length $T w_{\mathrm{i}}$. Then, the ideal response, $s(t)$ to the cut-out input pulse, $\hat{x}(t)$ is expressed as follows:

$$
s(t)= \begin{cases}w_{\mathrm{i}}(T) h(t-T), & t \geq 0 \\ 0, & \text { otherwise } .\end{cases}
$$

Here, we assume that the cut-out output signal, $\hat{y}(t)$ is the sum of the ideal response, $s(t)$ and the noise. Then, in case (b) shown in Fig. 2 (b), the noise, $n_{\mathrm{b}}(t)$ is expressed as follows:

$$
n_{\mathrm{b}}(t)= \begin{cases}-w_{\mathrm{i}}(T) h(t-T), & t>T w_{\mathrm{o}} \\ 0, & \text { otherwise } .\end{cases}
$$

The shaded section in the bottom figure expresses the noise, $n_{\mathrm{b}}(t)$.

In case (c) shown in Fig. 2 (c), the noise, $n_{\mathrm{c}}(t)$ is expressed as follows:

$$
n_{\mathrm{c}}(t)= \begin{cases}h(t-T)\left\{w_{\mathrm{o}}(t)-w_{\mathrm{i}}(T)\right\}, & 0 \leq t \leq T w_{\mathrm{o}} \\ 0, & \text { otherwise } .\end{cases}
$$

The shaded section in the bottom figure expresses the noise, $n_{\mathrm{c}}(t)$.

Next, an arbitrary signal, $x(t)$ is used as an input signal instead of the original impulse. Then, the cutout input and output signals, $\hat{x}(t)$ and $\hat{y}(t)$ are expressed as follows:

$$
\begin{aligned}
& \hat{x}(t)= \begin{cases}x(t) w_{\mathrm{i}}(t), & 0 \leq t \leq T w_{\mathrm{i}} \\
0, & \text { otherwise },\end{cases} \\
& \hat{y}(t)= \begin{cases}\int_{-\infty}^{T w_{\mathrm{o}}} x(T) h(t-T) w_{\mathrm{o}}(t) d T, \\
0, & 0 \leq t \leq T w_{\mathrm{o}} \\
0, & \text { otherwise . }\end{cases}
\end{aligned}
$$

Using Eq. (11), the ideal response, $s(t)$ to the cutout input signal, $\hat{x}(t)$ is expressed as follows:

$$
s(t)= \begin{cases}\int_{0}^{T w_{\mathrm{i}}} x(T) w_{\mathrm{i}}(T) h(t-T) d T, \\ 0, & t \geq 0 \\ 0 & \text { otherwise } .\end{cases}
$$

In the same case as that shown in Fig. 2 (a), the noise, $n_{\mathrm{a}}(t)$ is expressed as follows:

$$
n_{\mathrm{a}}(t)= \begin{cases}\int_{-\infty}^{0-\varepsilon} x(T) h(t-T) w_{\mathrm{o}}(t) d T, \\ 0 \leq t \leq T w_{0} \\ 0, & \text { otherwise, }\end{cases}
$$

where $\varepsilon$ is positive and $\varepsilon \rightarrow 0$.

In the same case as that shown in Fig. 2 (b), the noise, $n_{\mathrm{b}}(t)$ is expressed as follows:

$$
n_{\mathrm{b}}(t)= \begin{cases}-\int_{0}^{T w_{\mathrm{i}}} x(T) w_{\mathrm{i}}(T) & h(t-T) d T, \\ & t>T w_{\mathrm{o}} \\ 0, & \text { otherwise } .\end{cases}
$$

In the same case as that shown in Fig. 2 (c), the noise, $n_{\mathrm{c}}(t)$ is expressed as follows:

$$
n_{\mathrm{c}}(t)= \begin{cases}\int_{0}^{T w_{1}} x(T) h(t-T)\left\{w_{\mathrm{o}}(t)-w_{\mathrm{i}}(T)\right\} d T, \\ 0, \quad \text { otherwise } .\end{cases}
$$

Because of the above-mentioned three noises due to the windows, the effective signal-to-noise ratio is decreased, and the accuracy of the estimated impulse response is decreased.

From Eqs. (14), (15) and (16), the total noise, $n(t)$ 
Rectangle (Dirichlet) Window

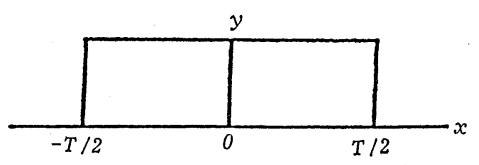

$$
\begin{aligned}
& y=1.0 \\
& x=-\frac{T}{2}, \ldots,-1,0,1, \ldots, \frac{T}{2}
\end{aligned}
$$

Triangle (Fejer, Bartlet) Window

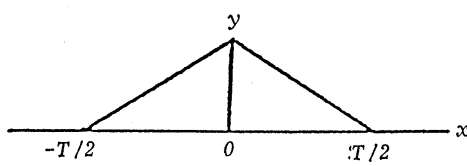

$$
\begin{aligned}
& y=1.0-\frac{|x|}{T / 2} \\
& x=-\frac{T}{2}, \ldots,-1,0,1, \ldots, \frac{T}{2}
\end{aligned}
$$

Half cosine Window

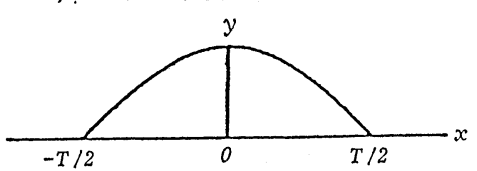

$$
\begin{aligned}
& y=\cos \left(\frac{x}{T} \pi\right) \\
& x=-\frac{T}{2}, \ldots,-1,0,1, \ldots, \frac{T}{2}
\end{aligned}
$$

Hamming Window

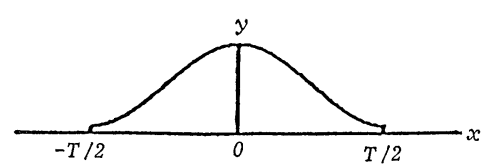

$$
\begin{aligned}
& y=0.54+0.46 \cos \left(\frac{2 \pi}{T} x\right) \\
& x=-\frac{T}{2}, \ldots,-1,0,1, \ldots, \frac{T}{2}
\end{aligned}
$$

\section{Hanning Window}

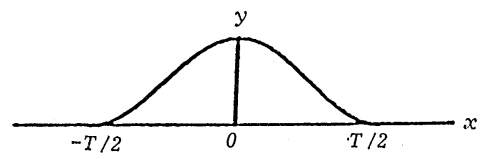

$$
\begin{aligned}
& y=0.5\left(1.0+\cos \left(\frac{2 \pi}{T} x\right)\right) \\
& x=-\frac{T}{2}, \ldots,-1,0,1, \ldots, \frac{T}{2}
\end{aligned}
$$

Riesz (Bochner, Parzen) Window

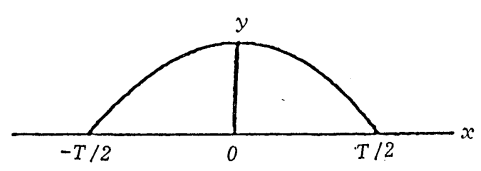

$$
\begin{aligned}
& y=1.0-\left|\frac{x}{T / 2}\right|^{2} \\
& 0 \leq|x| \leq \frac{T}{2}
\end{aligned}
$$

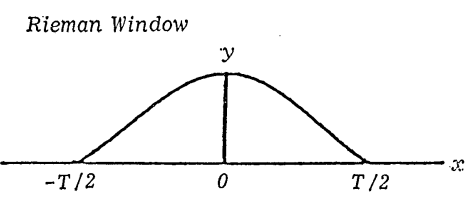

$$
\begin{aligned}
& y=\frac{\sin \left(\frac{x}{T} 2 \pi\right)}{\left(\frac{x}{T} 2 \pi\right)} \\
& 0 \leq|x| \leq \frac{T}{2}
\end{aligned}
$$

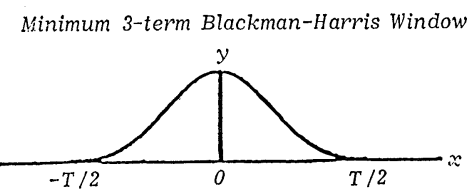

$$
\begin{aligned}
& y=a_{0}+a_{1} \cos \left(\frac{2 \pi}{T} x\right)+a_{2} \cos \left(\frac{2 \pi}{T} 2 x\right) \\
& 0 \leq|x| \leq \frac{T}{2} \\
& a_{0}=0.42323 \\
& a_{1}=0.49755 \\
& a_{2}=0.07922
\end{aligned}
$$

Fig. 3 Eight typès of time windows whose effect on the estimation of impulse responses were investigated. 


\section{ABE et al.: A NEW INVESTIGATION OF A TIME WINDOW}

is expressed as follows:

$$
n(t)=\left\{\begin{array}{cc}
\int_{-\infty}^{T w_{\mathrm{i}}} x(T) h(t-T) w_{\mathrm{o}}(t) d T \\
-\int_{0}^{T w_{\mathrm{i}}} x(T) w_{\mathrm{i}}(T) h(t-T) d T, \\
-\int_{0}^{T w_{\mathrm{i}}} x(T) w_{\mathrm{i}}(T) h(t-T) d T, \\
0, & t>T w_{\mathrm{o}} \\
0, & \text { otherwise. }
\end{array}\right.
$$

\section{CALCULATION OF THE SIGNAL-TO-NOISE RATIO FOR TWO SIMPLE CASES}

In this section, the signal-to-noise ratios are calculated for the cases where (1) a test signal is a white noise and the impulse response is represented by a delta function with a time delay; and (2) a test signal is a white noise and the impulse response is represented by an exponentially decaying white noise. The type and length of the time windows are the same for input and output signals. The shapes of the time windows investigated here are illustrated in Fig. 3.

When we estimate a time delay or an impulse response of a room, the accuracy of its estimate can be evaluated by an accuracy index. ${ }^{3)}$ The index takes a larger value as the accuracy of the estimate becomes higher. However, the maximum value of the index is limited to the ratio of the power of a signal to that of an external noise. In this paper we evaluate the accuracy in the case where the maximum value of the index is about $40 \mathrm{~dB}$.

\subsection{Delta Function with a Time Delay}

Since $x(t)$ is a white noise, the total power, $P_{\mathrm{s}}$ of the ideal response is represented from Section 2 as

$$
\begin{aligned}
\boldsymbol{P}_{\mathrm{s}} & =\int_{0}^{\infty}\{s(t)\}^{2} d t \\
& =\int_{0}^{\infty}\left\{\int_{0}^{T w_{\mathrm{i}}} x(T) w_{\mathrm{i}}(T) d\left(t-T_{\mathrm{d}}-T\right) d T\right\}^{2} d t \\
& \doteqdot \int_{0}^{\infty} x^{2}\left(t-T_{\mathrm{d}}\right) w_{\mathrm{i}}{ }^{2}\left(t-T_{\mathrm{d}}\right) d t \\
& \doteqdot \int_{0}^{\infty} x^{2}(t) w_{\mathrm{i}}^{2}(t) d t \\
& \fallingdotseq \int_{0}^{T w_{\mathrm{i}}} \sigma^{2} w_{\mathrm{i}}^{2}(t) d t
\end{aligned}
$$

where $d\left(t-T_{\mathrm{d}}\right)$ is a delta function with a time delay $T_{\mathrm{d}}$ and $\sigma^{2}$ the variance of the white noise.
On the other hand, the total power, $P_{\mathrm{n}}$ of the noise is represented as follows:

$$
\begin{aligned}
P_{\mathrm{n}}= & \int_{0}^{\infty}\{n(t)\}^{2} d t \\
= & \int_{0}^{T w_{\mathrm{o}}}\left\{\int_{-\infty}^{T w_{\mathrm{i}}} x(T) d\left(t-T_{\mathrm{d}}-T\right) w_{\mathrm{o}}(t) d T\right. \\
& \left.-\int_{0}^{T w_{\mathrm{i}}} x(T) w_{\mathrm{i}}(T) d\left(t-T_{\mathrm{d}}-T\right) d T\right\}^{2} d t \\
& +\int_{T w_{\mathrm{o}}+\varepsilon}^{\infty}\left\{-\int_{0}^{T w_{\mathrm{i}}} x(T) w_{\mathrm{i}}(T) d\left(t-T_{\mathrm{d}}-T\right) d T\right\}^{2} \\
& \times\{d t \\
= & \mid \begin{array}{l}
\int_{0}^{T w_{\mathrm{o}}}\left\{x\left(t-T_{\mathrm{d}}\right) w_{\mathrm{o}}(t)-x\left(t-T_{\mathrm{d}}\right) w_{\mathrm{i}}\left(t-T_{\mathrm{d}}\right)\right\}^{2} d t \\
+\int_{T w_{\mathrm{o}}+\varepsilon}^{\infty}\left\{x\left(t-T_{\mathrm{d}}\right) w_{\mathrm{i}}\left(t-T_{\mathrm{d}}\right)\right\}^{2} d t, \\
\int_{0}^{T w_{\mathrm{o}}}\left\{x\left(t-T_{\mathrm{d}}\right) w_{\mathrm{o}}(t)\right\}^{2} d t, \quad t<t \leq T w_{\mathrm{d}}+T_{\mathrm{d}}
\end{array} \\
& \left(\begin{array}{l}
\int_{0}^{T w_{\mathrm{o}}} \sigma^{2}\left\{w_{\mathrm{o}}(t)-w_{\mathrm{i}}\left(t-T_{\mathrm{d}}\right)\right\}^{2} d t \\
+\int_{T w_{\mathrm{o}}+\varepsilon}^{\infty} \sigma^{2} w_{\mathrm{i}}^{2}\left(t-T_{\mathrm{d}}\right) d t, \\
\int_{0}^{T w_{\mathrm{o}}} \sigma^{2}\left\{w_{\mathrm{o}}(t)\right\}^{2} d t, \quad t<T_{\mathrm{d}} .
\end{array}\right.
\end{aligned}
$$

From Eqs. (18) and (19), the signal-to-noise ratio, $\mathrm{S} / \mathrm{N}$ for a signal with a time delay is easily calculated from just the shape of time windows, as follows:

$$
\mathrm{S} / \mathrm{N}=10 \log _{10}\left(P_{\mathrm{s}} / P_{\mathrm{n}}\right) \text {. }
$$

The signal-to-noise ratios were calculated in the cases where the length of the time window was $T_{\mathrm{w}}=128$ and the delay time was $T_{\mathrm{d}}=2,4, \ldots, 64$. The results for various types of time windows are shown in Table 1 (a).

\subsection{Exponentially Decaying White Noise}

Since the input signal, $x(t)$ is a white noise which has no correlation with the impulse response, $h(t)$, the total power, $P_{\mathrm{s}}$ of the ideal response is represented as follows:

$$
\begin{aligned}
P_{\mathrm{s}} & =\int_{0}^{\infty}\left\{\int_{0}^{T w_{\mathrm{i}}} x(T) w_{\mathrm{i}}(T) h(t-T) d T\right\}^{2} d t \\
& =\int_{0}^{\infty}\left[\left\{\int_{0}^{T w_{\mathrm{i}}} x(T) w_{\mathrm{i}}(T) h(t-T) d T\right\}\right.
\end{aligned}
$$


Table 1 (a) Calculated signal-to-noise ratio in the case where the transfer function is expressed by a simple time delay.

\begin{tabular}{|c|c|c|c|c|c|c|c|c|}
\hline \multirow[b]{2}{*}{$2^{*}$} & \multicolumn{8}{|c|}{$1^{*}$} \\
\hline & Rectangle & Triangle & Half cosine & Hamming & Hanning & $\begin{array}{l}\text { Blackman- } \\
\text { Harris }\end{array}$ & Riesz & Riemann \\
\hline $1 / 2$ & 0.00 & -1.76 & -1.35 & -1.85 & -2.22 & -2.57 & -1.18 & -1.62 \\
\hline $1 / 4$ & 3.01 & 2.50 & 3.10 & 2.32 & 1.66 & 0.68 & 3.27 & 2.74 \\
\hline $1 / 8$ & 6.02 & 7.85 & 8.55 & 7.82 & 7.08 & 5.89 & 8.64 & 8.25 \\
\hline $1 / 16$ & 9.03 & 13.57 & 14.34 & 13.65 & 12.94 & 11.70 & 14.36 & 14.10 \\
\hline $1 / 32$ & 12.04 & 19.44 & 20.25 & 19.46 & 18.92 & 17.67 & 20.23 & 20.06 \\
\hline $1 / 64$ & 15.05 & 25.38 & 26.22 & 25.12 & 24.93 & 23.67 & 26.18 & 26.05 \\
\hline
\end{tabular}

$1^{*}:$ type of time window.

$2^{*}: T_{\mathrm{d}} / T_{\mathrm{w}}\left(T_{\mathrm{d}}\right.$ : length of time delay, $T_{\mathrm{w}}$ : length of time window).

Table 1 (b) Calculated signal-to-noise ratio in the case where the impulse response is expressed by an exponentially decaying white noise.

\begin{tabular}{|c|c|c|c|c|c|c|c|c|}
\hline \multirow[b]{2}{*}{$2^{*}$} & \multicolumn{8}{|c|}{$1^{*}$} \\
\hline & Rectangle & Triangle & Half cosine & Hamming & Hanning & $\begin{array}{l}\text { Blackman- } \\
\text { Harris }\end{array}$ & Riesz & Riemann \\
\hline $1 / 16$ & -1.50 & -1.82 & -1.74 & -1.82 & -1.90 & -2.00 & -1.72 & -1.79 \\
\hline $1 / 8$ & -0.42 & -0.95 & -0.80 & -0.97 & -1.13 & -1.32 & -0.75 & -0.89 \\
\hline $1 / 4$ & 1.41 & 0.65 & 0.92 & 0.59 & 0.31 & -0.05 & 1.01 & 0.75 \\
\hline $1 / 2$ & 4.02 & 3.36 & 3.80 & 3.26 & 2.82 & 2.19 & 3.94 & 3.53 \\
\hline 1 & 6.99 & 7.42 & 8.02 & 7.30 & 6.70 & 5.76 & 8.17 & 7.69 \\
\hline 2 & 10.00 & 12.53 & 13.23 & 12.47 & 11.76 & 10.63 & 13.33 & 12.91 \\
\hline 4 & 12.98 & 18.16 & 18.93 & 18.17 & 17.47 & 16.27 & 18.97 & 18.67 \\
\hline 8 & 15.98 & 23.97 & 24.76 & 23.91 & 23.43 & 22.19 & 24.76 & 24.56 \\
\hline 16 & 18.99 & 29.87 & 30.70 & 29.48 & 29.51 & 28.12 & 30.67 & 30.52 \\
\hline
\end{tabular}

$1^{*}:$ type of time window.

2*: $T_{\mathrm{w}} / T_{\mathrm{i}}\left(T_{\mathrm{w}}:\right.$ length of time window, $T_{\mathrm{i}}$ : length of impulse response).

$$
\begin{aligned}
& \left.\times\left\{\int_{0}^{T w_{\mathrm{i}}} x\left(T^{\prime}\right) w_{\mathrm{i}}\left(T^{\prime}\right) h\left(t-T^{\prime}\right) d T^{\prime}\right\}\right] d t \\
\doteqdot & \int_{0}^{\infty}\left\{\int_{0}^{T w_{\mathrm{i}}} x^{2}(T) w_{\mathrm{i}}{ }^{2}(T) h^{2}(t-T) d T\right\} d t \\
\doteqdot & \int_{0}^{\infty}\left\{\int_{0}^{T w_{\mathrm{i}}} \sigma^{2} w_{\mathrm{i}}{ }^{2}(T) \hat{h}^{2}(t-T) d T\right\} d t,
\end{aligned}
$$

where $\hat{h}(t)=A \exp \left(-3\left(T_{0} / 10\right) \cdot \log _{10} e\right)$ is the envelope of the impulse response.

On the other hand, the total power, $P_{\mathrm{n}}$ of the noise signal is represented as follows:

$$
\begin{aligned}
P_{\mathrm{n}}= & \int_{0}^{\infty}\{n(t)\}^{2} d T \\
= & \int_{0}^{T w_{\mathrm{o}}}\left\{\int_{-\infty}^{T w_{\mathrm{i}}} x(T) h(t-T) w_{\mathrm{o}}(t) d T\right. \\
& \left.-\int_{0}^{T w_{\mathrm{i}}} x(T) w_{\mathrm{i}}(T) h(t-T) d T\right\}^{2} d t
\end{aligned}
$$

$$
\begin{aligned}
& \quad+\int_{T w_{\mathrm{o}}+\varepsilon}^{\infty}\left\{-\int_{0}^{T w_{\mathrm{i}}} x(T) w_{\mathrm{i}}(T) h(t-T) d T\right\}^{2} d t \\
& =\int_{0}^{T w_{\mathrm{o}}}\left[\int_{-\infty}^{0-\varepsilon} x(T) h(t-T) w_{\mathrm{o}}(t) d T\right. \\
& \left.\quad+\int_{0}^{T w_{\mathrm{i}}} x(T) h(t-T)\left\{w_{\mathrm{o}}(t)-w_{\mathrm{i}}(T)\right\} d T\right]^{2} d t \\
& \quad+\int_{T w_{\mathrm{o}}+\varepsilon}^{\infty}\left\{-\int_{0}^{T w_{\mathrm{i}}} x(T) w_{\mathrm{i}}(T) h(t-T) d T\right\}^{2} d t \\
& \doteq \int_{0}^{T w_{\mathrm{o}}}\left[\int_{-\infty}^{0-\varepsilon} \sigma^{2} \hat{h}^{2}(t-T) w_{\mathrm{o}}{ }^{2}(t) d T\right. \\
& \left.\quad+\int_{0}^{T w_{\mathrm{i}}} \sigma^{2} \hat{h}^{2}(t-T)\left\{w_{\mathrm{o}}(t)-w_{\mathrm{i}}(T)\right\}^{2} d T\right] d t \\
& \quad+\int_{T w_{\mathrm{o}}+\varepsilon}^{\infty} \int_{0}^{T w_{\mathrm{i}}} \sigma^{2} w_{\mathrm{i}}{ }^{2}(T) \hat{h}^{2}(t-T) d T d t . \quad(22)
\end{aligned}
$$




\section{ABE et al: A NEW INVESTIGATION OF A TIME WINDOW}

Equations (21) and (22) mean that the signal-tonoise ratio is also calculated only from the shape of the time windows. Table 1 (b) shows the results for various types of time windows in the cases where the length of time window was $T_{\mathrm{w}}=8,16,32, \ldots, 2,048$, the length of the impulse response was 128 and the envelope $\hat{h}(t)$ of the impulse response was represented as follows:

$$
\hat{h}(p)= \begin{cases}10^{(-2 p / 27)}, & p=0,1, \ldots, 127 \\ 0, & \text { otherwise } .\end{cases}
$$

In general, the length of the impulse response is considered to be infinite. However, the impulse response becomes smaller in magnitude and is embed- ded in noise as time passes. Since the magnitude of the envelope $\hat{h(p)}$ is less than $1 / 100$ at $p>127$ in this case, a part of the impulse response, which is at $p>$ 127, is neglected and set to 0 in Eq. (23).

\section{RESULTS OF COMPUTER SIMULATION AND EXPERIMENTS}

To verify the above-described theoretical estimations, computer simulations and an experiment using a model room were carried out. We discuss hereafter the results with the index $A c_{\mathrm{s}}$ or the index $A c_{\mathrm{e}}{ }^{3)}$ which represent the accuracy of an estimated impulse response obtained by simulation or that obtained by experiment, respectively. The accuracy indices $A c_{\mathrm{s}}$ and $A c_{\mathrm{e}}$ are calculated as follows:

$$
\begin{gathered}
A c_{\mathrm{s}}=10 \log _{10}\left[\int_{0}^{\infty} h^{2}(t) d t / \int_{0}^{\infty}\{\hat{h}(t)-h(t)\}^{2} d t\right], \\
A c_{\mathrm{e}}=10 \log _{10}\left[\int_{0}^{\infty} o^{2}(t) d t / \int_{0}^{\infty}\left\{\int_{-\infty}^{t} x(T) \hat{h}(t-T) d T-o(t)\right\}^{2} d t\right],
\end{gathered}
$$

where $h(t)$ is the true impulse response, $\hat{h}(t)$ the estimated impulse response, $o(t)$ the observed output signal, and $x(t)$ the input signal.

The larger values of $A c_{\mathrm{s}}$ and $A c_{\mathrm{e}}$ indicate more accurate estimation.

\subsection{Computer Simulation}

When the impulse response of the system to be estimated is represented by a delta function with a time delay, the true impulse response is the delayed input signal. Ten different white noises were used as the input signals, and the output signals, that is, the responses to the input signals were calculated by computing the convolution between the input signals and the impulse response. The impulse responses were estimated by the cross-spectral technique and the index $A c_{\mathrm{s}}$ was calculated. Then, the mean value and the variance of the accuracy index $A c_{\mathrm{s}}$ were calculated, as shown in Table 2 (a).

For the case where an impulse response is represented by an exponentially decaying white noise, 10 different impulse responses were generated using 10 different white noises so that the envelope of the impulse responses was expressed by Eq. (23). For each impulse response, the accuracy index $A c_{\mathrm{s}}$ was calculated in the same way as described above. The mean values and the variances of the accuracy index $A c_{\text {s }}$ were calculated, as shown in Table 2 (b).

Comparing Tables 1 (a) and 1 (b) with Tables 2 (a) and $2(\mathrm{~b})$, it is found that a better signal-to-noise ratio gives a more accurate impulse response. A rectangular window offers better results than others, so long as the length of the time window is short. That is, the maximum value of $A c_{\mathrm{s}}$ is obtained by a rectangular window in the following two cases: (1) the impulse response is represented by a delta function with a time delay and the time delay is half of the length of the time window (see Table 2 (a)); (2) the impulse response is represented by an exponentially decaying white noise and its length is longer than that of the time window (see Table 2 (b)). On the contrary, a Riesz window or a half cosine window offers the best results in the following two cases: (1) the length of the time window is longer than a quarter of the time delay when the transfer function of the system to be estimated is expressed by a simple delay; (2) the length of the time window is longer than a quarter of that of the impulse response of the system when the impulse response is expressed by an exponentially decaying white noise (where the length of the impulse response is the distance between the initial time, $t=0$, and the time at which the envelope of the impulse response is $1 / 100$ in magnitude).

\subsection{Experiments Using a Model Room}

The size of the room used in the experiments was $3 \times 5 \times 8 \mathrm{~m}$. The reverberation time of the room was about $0.5 \mathrm{~s}$. A non-directional microphone was 
Table 2 (a) Calculated accuracy index $A c_{\mathrm{s}}$ in the case where the transfer function is expressed by a simple time delay.

\begin{tabular}{|c|c|c|c|c|c|c|c|c|}
\hline \multirow[b]{2}{*}{$2 *$} & \multicolumn{8}{|c|}{$1^{*}$} \\
\hline & Rectangle & Triangle & Half cosine & Hamming & Hanning & $\begin{array}{l}\text { Blackman- } \\
\text { Harris }\end{array}$ & Riesz & Riemann \\
\hline $1 / 2$ & $\begin{array}{c}6.005 \\
(0.073)\end{array}$ & $\begin{array}{c}2.537 \\
(0.049)\end{array}$ & $\begin{array}{c}3.373 \\
(0.061)\end{array}$ & $\begin{array}{c}2.348 \\
(0.046)\end{array}$ & $\begin{array}{c}1.618 \\
(0.033)\end{array}$ & $\begin{array}{c}0.886 \\
(0.019)\end{array}$ & $\begin{array}{c}3.702 \\
(0.066)\end{array}$ & $\begin{array}{c}2.820 \\
(0.053)\end{array}$ \\
\hline $1 / 4$ & $\begin{array}{l}12.085 \\
(0.201)\end{array}$ & $\begin{array}{l}11.160 \\
(0.183)\end{array}$ & $\begin{array}{l}12.388 \\
(0.173)\end{array}$ & $\begin{array}{l}10.814 \\
(0.181)\end{array}$ & $\begin{array}{c}9.533 \\
(0.159)\end{array}$ & $\begin{array}{c}7.573 \\
(0.144)\end{array}$ & $\begin{array}{l}12.719 \\
(0.172)\end{array}$ & $\begin{array}{l}11.665 \\
(0.172)\end{array}$ \\
\hline $1 / 8$ & $\begin{array}{l}18.048 \\
(0.227)\end{array}$ & $\begin{array}{l}21.796 \\
(0.370)\end{array}$ & $\begin{array}{l}23.158 \\
(0.289)\end{array}$ & $\begin{array}{l}21.780 \\
(0.322)\end{array}$ & $\begin{array}{l}20.424 \\
(0.301)\end{array}$ & $\begin{array}{c}18.169 \\
(0.321)\end{array}$ & $\begin{array}{l}23.317 \\
(0.288)\end{array}$ & $\begin{array}{l}22.601 \\
(0.296)\end{array}$ \\
\hline $1 / 16$ & $\begin{array}{l}24.162 \\
(0.319)\end{array}$ & $\begin{array}{l}32.395 \\
(0.459)\end{array}$ & $\begin{array}{l}33.694 \\
(0.367)\end{array}$ & $\begin{array}{l}32.594 \\
(0.429)\end{array}$ & $\begin{array}{l}31.533 \\
(0.404)\end{array}$ & $\begin{array}{l}29.534 \\
(0.524)\end{array}$ & $\begin{array}{l}33.717 \\
(0.375)\end{array}$ & $\begin{array}{l}33.345 \\
(0.353)\end{array}$ \\
\hline $1 / 32$ & $\begin{array}{l}30.247 \\
(0.625)\end{array}$ & $\begin{array}{l}42.035 \\
(0.438)\end{array}$ & $\begin{array}{l}43.105 \\
(0.464)\end{array}$ & $\begin{array}{c}42.089 \\
(0.542)\end{array}$ & $\begin{array}{c}41.571 \\
(0.415)\end{array}$ & $\begin{array}{c}40.054 \\
(0.598)\end{array}$ & $\begin{array}{c}43.056 \\
(0.501)\end{array}$ & $\begin{array}{l}42.915 \\
(0.407)\end{array}$ \\
\hline $1 / 64$ & $\begin{array}{c}37.134 \\
(0.831)\end{array}$ & $\begin{array}{l}52.314 \\
(0.454)\end{array}$ & $\begin{array}{c}53.233 \\
(0.634)\end{array}$ & $\begin{array}{l}51.567 \\
(0.594)\end{array}$ & $\begin{array}{l}52.021 \\
(0.505)\end{array}$ & $\begin{array}{c}50.765 \\
(0.609)\end{array}$ & $\begin{array}{l}53.152 \\
(0.677)\end{array}$ & $\begin{array}{l}53.120 \\
(0.549)\end{array}$ \\
\hline $\begin{array}{l}1^{*}: \\
2^{*}:\end{array}$ & $\begin{array}{l}\text { time wind } \\
T_{\mathrm{d}}: \text { length }\end{array}$ & w. & $T_{\mathrm{w}}$ : leng & of time & adow). & & & $\begin{array}{l}\text { mean value } \\
\text { (variance) }\end{array}$ \\
\hline
\end{tabular}

Table 2 (b) Calculated accuracy index $A c_{\mathrm{s}}$ in the case where the impulse response is expressed by an exponentially decaying white noise.

\begin{tabular}{|c|c|c|c|c|c|c|c|c|}
\hline \multirow[b]{2}{*}{$2^{*}$} & \multicolumn{8}{|c|}{$1^{*}$} \\
\hline & Rectangle & Triangle & Half cosine & Hamming & Hanning & $\begin{array}{l}\text { Blackman- } \\
\text { Harris }\end{array}$ & Riesz & Riemann \\
\hline $1 / 16$ & $\begin{array}{c}5.340 \\
(2.141)\end{array}$ & $\begin{array}{c}3.252 \\
(1.724)\end{array}$ & $\begin{array}{c}3.620 \\
(1.938)\end{array}$ & $\begin{array}{c}3.282 \\
(1.710)\end{array}$ & $\begin{array}{c}2.912 \\
(1.555)\end{array}$ & $\begin{array}{c}2.377 \\
(1.328)\end{array}$ & $\begin{array}{c}3.736 \\
(2.000)\end{array}$ & $\begin{array}{c}3.414 \\
(1.825)\end{array}$ \\
\hline $1 / 8$ & $\begin{array}{c}6.447 \\
(1.971)\end{array}$ & $\begin{array}{c}3.877 \\
(1.635)\end{array}$ & $\begin{array}{c}4.374 \\
(1.782)\end{array}$ & $\begin{array}{c}3.782 \\
(1.602)\end{array}$ & $\begin{array}{c}3.282 \\
(1.485)\end{array}$ & $\begin{array}{c}2.768 \\
(1.342)\end{array}$ & $\begin{array}{c}4.571 \\
(1.833)\end{array}$ & $\begin{array}{c}4.041 \\
(1.691)\end{array}$ \\
\hline $1 / 4$ & $\begin{array}{c}7.766 \\
(1.143)\end{array}$ & $\begin{array}{c}5.424 \\
(1.078)\end{array}$ & $\begin{array}{c}5.971 \\
(1.161)\end{array}$ & $\begin{array}{c}5.292 \\
(1.063)\end{array}$ & $\begin{array}{c}4.724 \\
(1.005)\end{array}$ & $\begin{array}{c}4.056 \\
(0.925)\end{array}$ & $\begin{array}{c}6.179 \\
(1.186)\end{array}$ & $\begin{array}{c}5.606 \\
(1.114)\end{array}$ \\
\hline $1 / 2$ & $\begin{array}{l}11.146 \\
(0.857)\end{array}$ & $\begin{array}{c}9.059 \\
(1.043)\end{array}$ & $\begin{array}{c}9.735 \\
(1.039)\end{array}$ & $\begin{array}{c}8.875 \\
(1.044)\end{array}$ & $\begin{array}{c}8.156 \\
(1.035)\end{array}$ & $\begin{array}{c}7.192 \\
(1.009)\end{array}$ & $\begin{array}{c}9.974 \\
(1.033)\end{array}$ & $\begin{array}{c}9.296 \\
(1.043)\end{array}$ \\
\hline 1 & $\begin{array}{l}16.247 \\
(0.708)\end{array}$ & $\begin{array}{l}15.094 \\
(0.880)\end{array}$ & $\begin{array}{l}16.019 \\
(0.859)\end{array}$ & $\begin{array}{c}14.841 \\
(0.884)\end{array}$ & $\begin{array}{l}13.861 \\
(0.907)\end{array}$ & $\begin{array}{l}12.488 \\
(0.934)\end{array}$ & $\begin{array}{l}16.314 \\
(0.851)\end{array}$ & $\begin{array}{l}15.439 \\
(0.872)\end{array}$ \\
\hline 2 & $\begin{array}{l}22.019 \\
(0.830)\end{array}$ & $\begin{array}{c}23.819 \\
(0.779)\end{array}$ & $\begin{array}{l}25.073 \\
(0.765)\end{array}$ & $\begin{array}{l}23.599 \\
(0.766)\end{array}$ & $\begin{array}{l}22.316 \\
(0.770)\end{array}$ & $\begin{array}{l}20.355 \\
(0.802)\end{array}$ & $\begin{array}{l}25.351 \\
(0.770)\end{array}$ & $\begin{array}{l}24.408 \\
(0.762)\end{array}$ \\
\hline 4 & $\begin{array}{l}27.257 \\
(0.820)\end{array}$ & $\begin{array}{l}33.319 \\
(0.951)\end{array}$ & $\begin{array}{l}34.999 \\
(0.926)\end{array}$ & $\begin{array}{l}33.417 \\
(0.967)\end{array}$ & $\begin{array}{l}32.153 \\
(0.949)\end{array}$ & $\begin{array}{l}29.834 \\
(0.947)\end{array}$ & $\begin{array}{l}35.204 \\
(0.910)\end{array}$ & $\begin{array}{l}34.369 \\
(0.945)\end{array}$ \\
\hline 8 & $\begin{array}{l}32.461 \\
(0.943)\end{array}$ & $\begin{array}{l}42.920 \\
(1.206)\end{array}$ & $\begin{array}{l}45.098 \\
(1.009)\end{array}$ & $\begin{array}{l}43.246 \\
(1.159)\end{array}$ & $\begin{array}{l}42.190 \\
(1.159)\end{array}$ & $\begin{array}{l}39.854 \\
(1.288)\end{array}$ & $\begin{array}{l}45.315 \\
(0.987)\end{array}$ & $\begin{array}{l}44.413 \\
(1.063)\end{array}$ \\
\hline 16 & $\begin{array}{l}37.156 \\
(1.147)\end{array}$ & $\begin{array}{c}49.704 \\
(1.142)\end{array}$ & $\begin{array}{l}52.249 \\
(1.132)\end{array}$ & $\begin{array}{l}50.221 \\
(1.257)\end{array}$ & $\begin{array}{c}49.541 \\
(1.255)\end{array}$ & $\begin{array}{l}47.300 \\
(1.263)\end{array}$ & $\begin{array}{l}52.566 \\
(1.090)\end{array}$ & $\begin{array}{l}51.513 \\
(1.195)\end{array}$ \\
\hline $\begin{array}{l}1^{*} \mathrm{t} \\
2^{*}:\end{array}$ & $\begin{array}{l}\text { time windc } \\
T_{\mathrm{w}}: \text { length }\end{array}$ & of time $\mathrm{w}$ & $0 \mathrm{w}, I_{1} \cdot 1$ & & & & & $\underset{\text { (variance) }}{\text { mean value }}$ \\
\hline
\end{tabular}

set $2 \mathrm{~m}$ apart from a loud-speaker. The signal-tonoise ratio was about $30 \mathrm{~dB}$. A continuous white noise was used as the input test signal. The test input signal and the output of the microphone were passed through low-pass filters and A/D converted at the sampling frequency of $6 \mathrm{kHz}$. The cut off frequency of the low-pass filter was $2 \mathrm{kHz}$.

The accuracy index $A c_{\mathrm{e}}$ was computed for 3 time windows: a rectangular window, a Hanning window, and a Riesz window. The effect of the length of each 


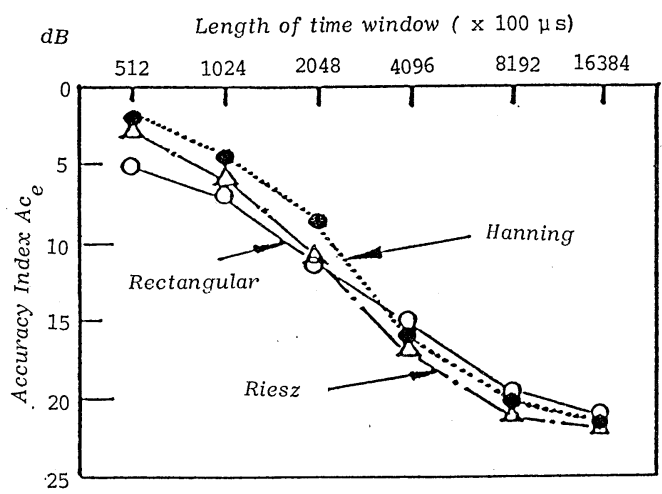

Fig. 4 Experimentally obtained accuracy index $A c_{\mathrm{e}}$ for three types of time windows.

time window on the accuracy index $A c_{\mathrm{e}}$ is shown in Fig. 4. As shown previously by the results of computer simulations, the best accuracy is again found to be achieved by a rectangular window when the length of the time window is short. In the case where the length of the time window is sufficiently long, the best accuracy is achieved by a Riesz window.

\section{CONCLUSION}

This paper describes the effect of a time window on the accuracy of impulse response estimation by the cross-spectral technique using a continuous signal as the source signal. First described is the fact that the signal-to-noise ratio is decreased even in the case of no external noise; this, because the length of the time window is finite. The method of calculating the signal-to-noise ratio from the shape of the time window is described in two typical cases where the impulse response is represented (1) by a delta func- tion with a time delay and (2) by an exponentially decaying white noise. The latter case is the simplest model of the impulse response of a room. Next, presented is the fact that the calculated signal-tonoise ratio coincides well with the accuracy of an estimated impulse response. Eight types of time windows were compared by computer simulation from the view point of accurate impulse response estimation. Three types of time windows were compared in an experiment using a model room, from the same view point as the computer simulation. From the computer simulations and the experiment, the following two facts were obtained: (1) a rectangular window offers the best results when the length of the time window is shorter than that of the impulse response, (2) a Riesz window offers the best results when the length of the time window is sufficiently long.

\section{ACKNOWLEDGMENTS}

Authors thank Dr. Y. Kawazoe and the group of R.C.A.I.S., Tohoku University for their useful advice and encouragement.

\section{REFERENCES}

1) J. Y. Chung, M. J. Crocker, and J. F. Hamilton, "Measurement of frequency responses and the multiple coherence function of the noise-generation system of a diesel engine," J. Acoust. Soc. Am. 58, 635-642 (1975).

2) G. H. Robertson, "Influence of data window shape on detectability of small CW signals in white noise," J. Acoust. Soc. Am. 67, 1274-1276 (1980).

3) C. D. Kim, M. Abe, and K. Kido, "Investigations on the method for the estimation of impulse response using a rectangular pulse,' J. Acoust. Soc. Jpn. (E) 7, 239-247 (1986). 